\title{
A pedagogia das políticas públicas de saúde: norma e fricções de gênero na feitura de corpos*
}

\author{
Michele de Freitas Faria de Vasconcelos** \\ Fernando Seffner***
}

\section{Resumo}

A finalidade deste artigo, inspirado e vitalizado por nossas inserções no campo da saúde pública, é pensar políticas corporais de subjetivação e de gênero inscritas no empreendimento da governamentalidade. As políticas públicas de saúde são entendidas como territórios de ensino, atuando como pedagogias engajadas na formatação de corpos marcados por normas regulatórias de gênero, mas também como territórios de (des)aprendizagem, na medida em que experimentações de gênero friccionam e subvertem tais normas, abrindo corpos ao descaminho.

Palavras-chave: Governamentalidade, Subjetividade, Políticas Públicas de Saúde, Corpo, Gênero.

\footnotetext{
* Recebido para publicação em 16 de agosto de 2013, aceito em 9 de janeiro de 2015.

** Professora do Departamento de Educação da Universidade Federal de Sergipe - UFS e pesquisadora no Grupo de Estudos em Educação e Relações de Gênero, da Faculdade de Educação, UFRGS, e no Grupo de Estudos e Pesquisas sobre Exclusão, Cidadania e Direitos Humanos, da UFS, Aracaju, SE, Brasil. michelevasconcelos@hotmail.com

**** Professor do Programa de Pós-Graduação em Educação e coordenador do Grupo de Estudos em Educação e Relações de Gênero, ambos na Universidade Federal do Rio Grande do Sul - UFRGS, Porto Alegre, RS, Brasil. fernandoseffner@gmail.com
} 
262 A pedagogia das políticas públicas de saúde

The Pedagogy of Public Health Policies: Standard and Gender Frictions in Making Bodies

\begin{abstract}
This article is inspired and vitalized by our inserts in the field of public health. The paper discusses the body of political subjectivity and gender entered in the project of governmentality. The public health policies are seen as areas of teaching, acting as pedagogies engaged in shaping regulatory standards bodies marked by gender. Public policies are also thought to territories (un)learning trials in which gender and rub subvert these rules, opening bodies astray.
\end{abstract}

Key Words: Governmentality, Subjectivity, Public Health Policies, Body; Gender. 
cadernos pagu (44) Michele de F. Faria de Vasconcelos e Fernando Seffner 263

\section{Do gênero vamos, ao gênero viemos}

Este texto emerge de uma indagação que tem acompanhado nossos modos de fazer-pensar pesquisa no campo das políticas públicas de saúde: qual pode ser a força de um olhar de gênero na produção de análises sobre o funcionamento de tais políticas? Em particular, qual pode ser a potência de um empreendimento analítico que pretende investigar arranjos corporais - corpo institucional, terapêutico, corpo de profissionais e usuári* ${ }^{1}$ - tecidos no bojo de tais políticas, a partir da lente do gênero? Esta escrita produz-se, pois, como tentativa de tatear respostas possíveis, embora locais e contingenciais. Mais do que isso, pretendemos com essa pergunta multiplicar caminhos de análise, pois perguntar parece ser onde tudo começa, turvando certezas claras e razoáveis, problematizando o que parece óbvio na paisagem das políticas públicas, nas montagens corporais e nas feituras de gênero aí produzidas.

No sentido de construir um percurso de discussão, partamos, pois, de uma limitação que tende a se fazer presente nas análises de gênero desenvolvidas no terreno das políticas públicas de saúde: em decorrência de certo contexto históricopolítico-epistemológico (Scott, 1995; Corrêa, 2001), o conceito de "gênero" tendeu a se construir como sinônimo de "mulheres". Nesse terreno, gênero tendeu ( $e$ ainda tende) a se equivaler $e$ a se restringir à noção constructo mulher-heterossexual-mãe (Corrêa, 2002). Desse modo, as discussões de gênero costumam se desenvolver restritas ao departamento "saúde da mulher" ${ }^{2}$, que

\footnotetext{
1 Neste artigo, utilizamos asterisco (*) em lugar de o/a, mantendo a direção de ir de encontro a uma linguagem que tende a universalizar o masculino, mas desfazendo-nos do uso da dicotomia masculino/feminino, por meio da qual se tende a fixar e essencializar maneiras de fazer gênero em apenas duas extremidades. A tentativa foi de, também pela escrita, experimentar um "desfazer o gênero" (Butler, 2007), explicitando sua condição de multiplicidade.

2 Mais recentemente, pensando gênero como categoria relacional, mas um relacional de dois termos pré-fixados, assistimos o mesmo movimento insular da "saúde do homem".
} 
visita, de vez em quando, outros departamentos e serviços de saúde. Exemplos dessa restrição podem ser percebidos, quando, nos serviços de saúde mental em que trabalhamos/pesquisamos, atividades intituladas "de gênero" se limitavam a grupos de mulheres; ou quando, no cenário da Rede Cegonha, criada no bojo do Ministério da Saúde no ano de 2011 com o objetivo de qualificar a atenção obstétrica $e$ infantil, o direito a acompanhante no momento do parto é descrito como "direito à acompanhante de livre escolha da mulher", limitando-se a função do homem-pai a um convidado - quando o é - a participar do momento de nascimento $\mathrm{d}^{*}$ filh*. Além disso, sob a alegação de manter a privacidade de outras parturientes, a livre escolha é garantida, desde que seja "uma" acompanhante, uma outra mulher. Nesse caso, o protagonismo da mulher parece alijar o protagonismo do homem no momento do parto.

Acompanhando as indicações de algumas feministas, que desenvolvem suas discussões valendo-se de abordagens pósestruturalistas (Corrêa, 2001; Louro, 2004, 2007; Bento, 2006; Butler, 2007; Meyer, 2008; Paraíso, 2011), num momento histórico em que as normas de gênero ainda são imprescindíveis na montagem dos corpos humanos e de suas identidades, parece ser fundamental problematizar a forma como se vem utilizando a categoria gênero em pesquisas e nas políticas sociais, em particular, nas políticas de saúde: os modos de uso de tal categoria têm funcionado a favor ou como modo de resistir à naturalização de regimes de verdade que apontam um "lugar "natural' e fixo para cada gênero" (Louro, 2007:32), escamoteando-se, assim, as relações de poder que estiveram e estão em exercício na produção e reiteração de tais regimes? Parece que enquanto o gênero funcionar como um vetor de subjetivação colado a determinadas formas masculinas $e$ femininas, se permanecerá discutindo, descrevendo e reificando inclusive nas pesquisas - papéis e funções de homens e mulheres, se resumindo o campo de leitura de gênero a atributos $e$ comportamentos do feminino e do masculino, e não se discutirão os atravessamentos de gênero nas políticas sociais, generificação que tende a se refletir também nos arranjos institucionais e nos 
modos de cuidado ali forjados. Naturalizando o gênero ou resumindo o olhar de gênero à constatação de dinâmicas sociais postas, não se desenvolverá, a partir de tal categoria, um trabalho de análise, intervenção $e$ (trans)formação nas políticas e nos serviços de saúde, junto a gestor*s, trabalhador*s e usuári*s, junto a tod*s e cada um* de nós.

$\mathrm{Na}$ tentativa de produzir deslocamentos na "miopia de gênero" supracitada, pretendemos, em nossas pesquisas, analisar arranjos corporais tecidos no bojo de políticas e serviços de saúde pública entendendo gênero como "categoria analítica de poder" (Scott, 1995) não restrita à mulher, nem à relação entre homens $e$ mulheres. Pensar gênero como um operador de análises de políticas públicas de saúde parece ser um caminho de pesquisa interessante, na medida em que tais políticas são tecidas também de modo generificado, operando distribuições de poder por meio de pedagogias corporais que tendem a reificar normas regulatórias de gênero. E tais normas se corporificam nos espaços físicos, nas relações entre profissionais e usuári*s dos serviços, na construção dos projetos terapêuticos e institucionais etc.

A partir do entendimento de que há um atravessamento de gênero na produção da gestão e do cuidado em saúde e de que a incorporação de formas específicas de subjetivar feminilidades $e$ masculinidades se reverte em práticas específicas de produção de saúde, parece ser interessante produzir, com o empreendimento de pesquisa e de escrita, espaços coletivos de discussão sobre gênero, ensaiando outros modos de uso de tal conceito $e$ rastreando outras formas de experimentar gênero $e$ de (co)fomentar sua normatividade bem ali no bojo das políticas de saúde.

Seguindo a diferenciação que Canguilhem (1978) desenvolve entre normalidade (normas impostas aos corpos) $e$ normatividade (normas produzidas pelos corpos) e a indicação de Butler (2007) da necessidade de desfazer o gênero, ao invés de restringir o campo de análise à investigação da produção de corpos por meio de sujeição a normas regulatórias, o que temos intentado em nossas pesquisas é seguir alguns ensaios corporais, 
algumas movimentações de corpos de profissionais e usuári*s, do corpo institucional $e$ do cuidado que tendem a esgarçar as pedagogias e normalidades operadas no campo das políticas públicas de saúde; corpos que parecem experimentar um "ir dando-se forma" pela produção de normas outras de gênero que desfazem a naturalização de normas regulatórias, às quais esses mesmos corpos tendem a se sujeitar.

\section{A governamentalidade como pedagogia corporal}

Você será organizado, você será um organismo, articulará seu corpo - senão será um depravado. Você será significante e significado, intérprete e interpretado - senão será desviante. Você será sujeito e, como tal, fixado, sujeito de enunciação rebatido sobre um sujeito de enunciado - senão você será apenas um vagabundo (Deleuze \& Guattari,

1996:22).

Almejamos pensar gênero como uma norma regulatória que funciona no interior de um campo de normalização mais amplo, qual seja, o da biopolítica e da governamentalidade das condutas humanas. Michel Foucault (1999, 2001a, 2001b) intitula de biopoder a economia de poder que se gesta na modernidade e se modula na contemporaneidade de nossas sociedades, a qual tem a vida humana como alvo, almejando empreender sua gestão.

Ao passo que o exercício de poder vai situar-se no nível da própria vida e suas intervenções recairão sobre seres vivos, essa forma de poder, para funcionar, precisará tocar o corpo: "é o fato do poder encarregar-se da vida [...] que lhe dá acesso ao corpo" (Foucault, 2001a:134). Dessa forma, o biopoder, antes de tudo, investiu e investe na carne, no biológico, no somático, no corporal: por meio de suas tecnologias disciplinares ${ }^{3}$ (anatomo-

3 Mais detalhes sobre o funcionamento do poder disciplinar, ver Foucault (2001a, 2001b, 2004). 
políticas) e de regulação populacional ${ }^{4}$ (biopolíticas da espécie humana), "o poder penetrou no corpo, encontra-se exposto no próprio corpo" (Foucault, 2001b) e produz efeitos sobre ele. Os corpos individual e social tornam-se "realidades biopolíticas" (Foucault, 2001b). Com o nascimento do biopoder, a vida e o corpo tornam-se elementos políticos que precisam ser administrados, calculados, geridos, normalizados.

No início dos anos 1980, em um dado momento do desenvolvimento de suas pesquisas, na busca por caminhos para extrapolar a crítica de que o sujeito por ele pensado seria efeito apenas de relações de sujeição, Foucault (2008a, 2008b, 2006c, 2011) fez um deslocamento na chave de compreensão das relações de poder, entendendo-as, a partir de então, como relações de governo:

[...] tentei esboçar um pouco essa noção de governo que me pareceu ser muito mais operatória que a noção de poder; governo entendido seguramente não no sentido restrito e atual de instância suprema de decisões executivas $e$ administrativas em um sistema estatal, mas no sentido largo e antigo de mecanismos e procedimentos destinados a conduzir os homens, a dirigir a conduta dos homens (Foucault, 2011:53).

Um governo entendido como arte de gerir a vida humana preocupar-se-á em como se encarregar dos indivíduos e da população, como intervir sobre eles de modo a conduzir suas condutas. Foi justamente no quadro geral dessa noção de governo como operador analítico das relações de poder que o autor forjou o conceito de governamentalidade para pensar o nascimento $e$ o modo de funcionamento da racionalidade do Estado moderno (Foucault, 2008a), bem como a emergência do (neo)liberalismo (Foucault, 2008b), entendendo-os como artes de

${ }^{4}$ Mais detalhes a respeito dos mecanismos reguladores da população em Foucault (2008a). Cabe lembrar, ainda, que, nas intituladas "sociedades da normalização" (Foucault, 1999), dá-se a coexistência de tecnologias disciplinares e de regulação da população. 
governar, como certas maneiras de governar que supõem uma dada racionalidade. A esse respeito o autor diz:

[...] O governo dos homens pelos homens - quer eles formem grupos modestos ou importantes, quer se trate do poder dos homens sobre as mulheres, dos adultos sobre as crianças, de uma classe sobre a outra, ou de uma burocracia sobre uma população - supõe uma certa forma de racionalidade, e não uma violência instrumental. Consequentemente, os que resistem ou se rebelam contra uma forma de poder não poderiam contentar-se em denunciar a violência ou em criticar uma instituição. [...]. O que é preciso colocar em questão é a forma de racionalidade com que se depara. [...]. A questão é: como são racionalizadas as relações de poder? Apresentá-la é a única maneira de evitar que outras instituições, com os mesmos objetivos e os mesmos efeitos, tomem seu lugar (Foucault, 2006b:35).

$\mathrm{Na}$ direção de entendermos a racionalidade da governamentalidade, parece ser preciso assinalar que, para fazer a gestão das condutas humanas, utilizaram-se ( $e$ ainda se utilizam) como âncora as técnicas inspiradas na experiência milenar do pastorado cristão:

o pastorado esboça o prelúdio da governamentalidade pela constituição específica de um sujeito que é sujeitado em redes específicas de obediência, que é subjetivado pela extração da verdade que lhe é imposta (Foucault, 2008a:243).

O elemento-chave para fazer a gestão estatal e (neo)liberal das condutas de uma forma eficaz já foi dado pelo exercício de poder pastoral: produzir subjetividades obedientes às finalidades da economia de poder, entendendo aqui subjetividade "enquanto produzida por instâncias individuais, coletivas e institucionais" (Guattari, 2000:11). A arte de governar é entendida, assim, como arte de fazer-se obedecer. Nesse quadro, o governo das condutas 
humanas vai exigir não somente atos de obediência $e$ de submissão, mas também atos de verdade, ou seja, um governo das condutas pela manifestação da verdade sob a forma da subjetividade como "expressão corpórea dos regimes de verdade de um tempo" (Paulon, 2005:21).

Gesta-se, assim, um exercício de poder, uma arte biopolítica de governar que, ancorando-se em procedimentos pastorais, vai permanecer $e$ atualizar a exigência de que os indivíduos não somente obedeçam, mas sejam obrigados a manifestar em verdade aquilo que são. Que digam, que confessem obstinadamente: "eis aquilo que eu sou, eu que obedeço" (Foucault, 2011:76) ou, em versões mais atuais, em que se prima pela produção de bioidentidades (Ortega, 2008), "mostro-lhes o meu corpo, aquilo que sou, eu que obedeço e participo da dinâmica social". Na medida em que se trata do esboço e da atualização de uma forma de poder que se configura como uma atividade cuja indexação depende de uma subjetividade (Avelino, 2011), de um eu, um si, pode-se dizer que a governamentalidade tem sua força localizada justamente na tomada de poder sobre a produção de subjetividade (Guattari e Rolnik, 2000). Ou seja, a arte biopolítica de governar funciona por meio da indexação das subjetividades ao exercício do biopoder. A partir de tais considerações, se pode entender governamentalidade como uma economia de produção de subjetividades entre Estado e mercado (Vasconcelos, 2013). Disso decorre a alegação foucaultiana (2006c:306) de que "a reflexão sobre a noção de governamentalidade [...] não pode deixar de passar, teórica $e$ praticamente, pelo âmbito de um sujeito que seria definido pela relação de si para consigo". Há, assim, um encadeamento entre poder, governo e si mesmo: "não há produção de obediência possível sem tecnologias de si, [...] práticas de relação de si consigo produtoras de estados de obediência" (Avelino, 2011:32). Para realizar o governo biopolítico das condutas humanas, são necessárias, então, tecnologias de si responsáveis por capturar e produzir certas relações de si para consigo, ancoradas em certas verdades sobre os sujeitos e seus corpos. 
Nesse sentido, pode-se pensar a condução das condutas como um problema pedagógico (Vasconcelos, 2013). O governo das condutas parece traduzir-se em uma pedagogia das condutas, na medida em que "é muito mais do lado do adquirido, ou seja, da constituição mais ou menos voluntária de um capital humano no curso da vida dos indivíduos, que se colocam todos os problemas" (Foucault, 2008b:315). Dessa forma, são necessários investimentos educacionais para formar sujeitos governáveis, que, nos dias atuais, se traduzem em empresários de si ou, ainda, para (re)formar ingovernáveis extraviados, na tentativa de inscrever suas condutas no modelo econômico de existência. Tais investimentos educacionais são, pois, compostos por todo um conjunto de processos de ensino e aprendizagem por meio dos quais indivíduos são transformados em sujeitos de uma determinada cultura, em terrenos de capitalismo financeiro, em sujeitos de uma dada cultura somático-empresarial. É nesse mesmo sentido que Seffner (2012) afirma que todo ato pedagógico é um ato político, dado que diz respeito a um jogo de poderes que posiciona os indivíduos como mais ou menos sujeitos a partir das marcações e organizações de seus corpos, a partir de sua maior ou menor submissão às artes de governar.

Em outras palavras, é preciso o funcionamento de um Estado e de um mercado pedagogos: é preciso produzir formas de ação, ensinar aos indivíduos e à população as condutas concernentes aos jogos de poder, organizando seus corpos. Nesse sentido, se há intervencionismo social permanente e multiforme é justamente como "condição histórica e social de possibilidade para uma economia de mercado" (Foucault, 2008b:222), pois é preciso formar capital-competência, subjetividades empresariais, condutas governáveis na medida em que as mesmas se traduzam em condutas econômicas. Nessa direção, todas as questões de seguridade, de higiene pública, de proteção à saúde e ao bemestar, de assistência, todas as políticas sociais e seu serviços são entendidos como elementos com possibilidade de incrementar o capital humano, ou seja, como elementos pedagógicos: porque é 
preciso formar empresários/as de si mesmos/as, porque é preciso alimentar o capital com vidas e corpos humanos.

O entendimento do governo biopolítico das condutas como pedagogia parece, pois, oferecer uma pista importante para analisar o funcionamento das políticas públicas de saúde: os serviços de saúde, seu espaço, as prescrições clínico-institucionais que os regem, suas rotinas $e$ atividades, as relações entre as pessoas que vivem, convivem e ali circulam, o modo como elas se comportam ali dentro, os saberes e fazeres ali desenvolvidos, o cuidado ofertado, os projetos terapêuticos construídos, toda essa maquinaria parece operar como pedagogias, como elementos formadores de condutas: gestos são inscritos nos corpos, processos de ensino-aprendizagem ali se tecem, organizando corpos, constituindo sujeitos, ou seja, formando profissionais $e$ usuários/as, personagens que ali se encontram, "cada um com uma função, um lugar, um rosto bem-definido" (Foucault, 2010:285-286). A arquitetura dos elementos pedagógicos nos espaços das políticas de saúde obedece, assim, à noção de currículo, entendido aqui não apenas como sinônimo de percurso de formação, mas como campo de tensão e negociação entre saberes, poderes e verdades (Seffner, 2012).

O projeto governamental almeja, pois, por meio de uma política educacional inscrita nas políticas de saúde, prender corpos a identidades, formas e limites, a um rosto homogêneo e "ideal": a humanidade. Com a finalidade de garantir determinada e reta direção na construção dos corpos de homens e de mulheres, fez-se e faz-se imprescindivel a produção continuada, constantemente atualizada e reiterada de uma determinada política de educação dos corpos, garantida por práticas pedagógicas formais $e$ informais. Com o objetivo de organizar os corpos, veiculam-se práticas educativas, participativas, inclusivas e, com elas, pedagogias corporais.

Nesse sentido é que entendemos as políticas de saúde como "territórios de ensino" (Paraíso, 2011). Tais políticas têm o escopo de formar sujeitos participativos, indexados a uma subjetividade cidadã. $\mathrm{O} / \mathrm{a}$ cidadão/ã participante, o indivíduo crítico, conhecedor 
de seus direitos e deveres, responsável pelo seu corpo $e$ autovigilante de suas condutas funciona como "avatares que povoam os territórios das pedagogias contemporâneas" (Corazza e Silva, 2003:11), ocupados em formar unidades-empresa, indivíduos que autopoliciam suas condutas $e$ a dos outros, na busca pela qualidade de vida da população da qual fazem parte. Nos serviços que compõem as políticas sociais, chamadas políticas de inclusão, acionam-se pedagogias que ensinam uma "cidadania de sujeição", a partir da qual se produz uma "autonomia regulada" (Carvalho, 2009), em que a garantia de direitos se faz acoplada ao controle das condutas. Ou seja, o direito à liberdade tem sua garantia subordinada ao cumprimento de deveres. Construída dessa forma, a condição do/a cidadão/ã de direitos "não é natural nem libertária, pois está condicionada a uma série de regras e lógicas assentadas na boa conduta" (Scheinvar, 2011:146).

A inclusão de corpos não cadastrados nos bancos de crédito no regime de cidadania, entendida como prática governamental, parece, então, ter o objetivo de incluir os excluídos como tal, trazê-los para espaços de participação e de convivência social num momento em que se exige participação social de todos/as. Passetti (2003:44) assinala, ainda, a importância do estímulo e do reforço à participação também desses "falsos vivos" nos jogos de poder:
a participação imperativa faz crer $e$ faz produzir um indivíduo que precisa mostrar que está vivo. Se não estiver segundo a produção [...] está enquanto agente político de participação democrática [...] de todos (vivos e mortos produtivos).

Tal modo de inclusão, operado mediante aproximação física entre os corpos "produtivos"/ativos e os não regrados, não permite que, ao se desenvolver análises, se prossiga falando apenas em "excluídos" - uma vez que uma boa parte "desses" também compõe os mapas de intervenção estatal, dado que as ovelhas desgarradas do controle das condutas devem retornar ao 
cadernos pagu (44) Michele de F. Faria de Vasconcelos e Fernando Seffner 273

rebanho - nem em exclusão de acesso a redes assistenciais (Lopes, 2011).

Exemplos desse movimento de formatação corporal por meio de pedagogias inscritas e operando em serviços de saúde, desdobrando-se sobre o cuidado ofertado, puderam ser observados por meio de nossa inserção-trabalho-pesquisa num Centro de Atenção Psicossocial para Álcool e outras Drogas CAPS ad (Vasconcelos, 2013). Aqui, como forma de pensarmos em como essas pedagogias forma $(\mathrm{ta}) \mathrm{m}$ corpos no cotidiano de serviços de saúde, destacaremos brevemente uma movimentação/limitação corporal.

Bermudas e camisetas largas, correntes de metal e anéis adornam o corpo d* usuári*; o rap é o estilo musical de sua preferência; cabelos curtos, voz grave e rouca, sorriso malandro misturado a um ar sisudo; palavras poucas e contundentes; olhar altivo, andar gingado mesclado a um mancar permanente; sandálias e pés "gastos", que fazem lembrar os pés de tantos outr*s usuári*s do CAPS ad. Um ingrediente a mais "revela" que esse corpo usuário de drogas e de CAPS, de periferia, desempregado, sem poder de endividamento, é um "anormal" (Foucault, 2001c), um corpo "abjeto" (Butler, 2007), um "infame" (Foucault, 2006a), que não existe para outra coisa senão para assinalar o limite do humano, para delimitar a fronteira de vidas dignas de serem vividas; um corpo desviante que precisa de tutela a fim de desligar-se de sua animalidade e trilhar caminhos humanos. Além de todas as características citadas acima, esse corpo é identificado como um corpo de mulher: uma usuária. Uma usuária com "trejeitos" masculinizados e gosto pelas mulheres como parceria sexual. Mas um corpo-mulher não é para ser feminino - um feminino essencializado, diga-se de passagem e para desejar sexualmente corpos-homens? Não é esse o caso. Se não o é, a ousadia desse corpo de ter se "apropriado", ter se feito a partir de elementos de masculinidades não precisaria ser contida? Precisaria?

Um corpo que faz uso considerado "indevido" de álcool $e$ outras drogas como também uso "indevido" de gênero. À primeira 
vista, o cuidar desse corpo parece articular-se com a necessidade de formatar corpos, de culpabilizar sujeitos e seus corpos, individualizá-los, corrigir/(re)abilitar suas condutas, trazer as vidas infames para a claridade do mundo humano, um mundo regulado por normas de gênero, um mundo supostamente sem drogas. Para tanto, traduzido por saberes especialistas que circulam no bojo das políticas de saúde, esse corpo identificado como "anormal", como vida infame indigna de ser vivida, posto que ultrapassou um possível pré-estruturado para os corpos humanos, precisa ser submetido a práticas de saúde a fim de ser corrigido reconduzido, normalizado, incluído.

Tachados como usuários de CAPS e de álcool e outras drogas, corpos tendem a sufocar numa emboscada cujos limites identitários são dados do seguinte modo: de um lado, a humanidade, da qual se pretende, por meio do "cuidado", que eles retornem a fazer parte, colando-se à forma-Homem, corpo sexuado e generificado, heterossexual, trabalhador, consumidor, empreendedor de si; de outro, a identidade-abjeção, "dependente químico", corpo usuário de álcool e outras drogas, que diz da animalidade desses corpos. Expondo seus corpos às políticas de saúde, práticas de poder o iluminam, intervêm sobre eles, o educam, o incluem na tentativa de produzir mudanças em seus "estilos de vida", rumo à sua qualificação: qualificação desses corpos e dessas vidas. Mediante o poder de inscrever condutas por meio de acionamento de pedagogias corporais, tais práticas (de saúde) irão decidir entre a animalização desses corpos, caso eles se mantenham não desejando o cuidado e o "arreio" e, assim, justificar a sua morte; ou entre a reanimação desses falsos vivos, humanizando-os, restabelecendo sua saúde, mediante vigilância cotidiana, inclusive dos próprios corpos sobre si mesmos e, com ela, sua humanidade, permitindo sua "integração" à cidade, ao mundo humano.

Nessa direção, estamos entendendo o funcionamento das práticas institucionais e terapêuticas operadas no interior das políticas e serviços de saúde como "biopedagogias" (Harwood, 2009), pedagogias corporais, dentre as quais, pedagogias de 
gênero e sexualidade. Os "territórios de ensino" (Paraíso, 2001) das políticas e serviços de saúde tendem a veicular um dado currículo de gênero cujo objetivo é formatar corpos. O corpo aparece, assim, como construto político-cultural, e o fazer em saúde como instância pedagógica por meio da qual se imprimem marcas nos corpos, incluindo-se marcas de gênero, sujeitando-os, organizando-os, normalizando-os, fazendo-os governáveis.

\section{Da formação de corpos sexuados, generificados e sexualizados}

Os corpos não são [...] tão evidentes como usualmente pensamos. Nem as identidades são uma decorrência direta das "evidências" dos corpos. De qualquer forma, investimos muito nos corpos. De acordo com as mais diversas imposições culturais, nós os construímos (Louro, 2007:15).

Até aqui, apontamos a governamentalidade como uma economia de produção de subjetividades $e$, desse modo, o problema do governo, o problema da condução das condutas, como um problema pedagógico. Na medida em que investimentos educacionais são fundamentais para formar corpos organizados $e$ sujeitos governáveis, as políticas de saúde veiculam pedagogias institucionais, terapêuticas, corporais. Dentre elas, destaquem-se as pedagogias de gênero $e$ de sexualidade, que são aquelas que mais de perto interessam para o recorte de nossas pesquisas (Bento, 2006; Louro, 2004, 2007).

"Em alguma época do século XVIII, o sexo que nós conhecemos foi inventado" (Laqueur, 2001:189). Ou seja, no então nascente cenário biopolítico moderno, criou-se a noção da "bisexualidade" originária: diferenças sexuais radicais e naturalizadas entre homens e mulheres que tendem a "justificar" sua destinação também "natural" à heterossexualidade (Seffner, 2003). A partir daí, o sexo "biológico" apareceu como evidência maior da identidade "humana": 
"Despertai jovens, de vossos gozos ilusórios; despojai-vos de vossos disfarces e lembrai-vos de que tendes apenas um verdadeiro sexo!".

"Não nos enganemos a respeito de nosso sexo"!

"A ordem sexual é onde devemos procurar nossa verdadeira e definitiva identidade"! (Foucault, 2006d:85).

Uma vez que a biopolítica inaugura uma "época em que a verdade última das condutas deverá ser buscada no corpo" (Bento, 2006:109), é nessa mesma arena que se constrói o dimorfismo sexual: ou se existe como um corpo-homem ou como um corpomulher. Dessa forma, estratégias de poder se articulam para veicular regimes de verdade que enunciam que a veracidade derradeira dos corpos e sujeitos humanos encontra-se em seu sexo. "O sexo é uma das normas pelas quais 'alguém' simplesmente se torna viável, que qualifica um corpo para a vida inteligível" (Bento, 2006:89). E, assim, formam-se os corpos humanos: corpos sexuados e generificados. "Se a sociedade divide-se em corpos-homens e corpos-mulheres, aqueles que não apresentam essa correspondência fundante tendem a estar fora da categoria do humano" (Bento, 2006:25).

Da naturalização do dimorfismo sexual como uma dimensão fundante da categoria do humano, decorre a necessidade de se saber logo o sexo do bebê, ter a certeza de que ele está seguro, abrigado em um dos lados da série binária instaurada. Caso essa diferenciação não ocorra, instala-se a urgência biomédica, representante da normalização, em interferir na ambiguidade $e$ delimitar, sem vacilo, o sexo $d^{*}$ bebê. A angústia dos pais, da família, da comunidade, da sociedade encontra-se materializada nas intervenções precoces da equipe de saúde.

Ressalte-se aqui o questionamento de Corrêa (2004) acerca do porquê, em nossas sociedades, dessa mutilação sexual não ser problematizada como o é pelas pessoas que a estudam nas ditas "sociedades primitivas".

Convenções disciplinares [...] regem a discussão dessas intervenções sobre o corpo na nossa sociedade e em outras 
cadernos pagu (44) Michele de F. Faria de Vasconcelos e Fernando Seffner 277

sociedades: convenções médicas, convenções jurídicas, convenções antropológicas, entre outras (Corrêa, 2004:174).

Desse modo, pode-se dizer que "o corpo já nasce maculado pela cultura" (Bento, 2006:89). "Os corpos já nascem operados. [...] todos estamos já mais ou menos operados(as) por tecnologias sociais precisas. Todos somos pós-operados" (Bento, 2006:89).

Nossos corpos se gestam e se organizam por meio de marcas político-culturais. Essa é a chave de compreensão deste texto, que se tece na contramão de posicionamentos fundamentalistas e substancialistas. Do mesmo modo como pensamos nesta escrita o corpo, concebemos aqui sexo, gênero e sexualidade não como objetos naturais, mas como construções político-culturais (Louro, 2004, 2007). Não pretendemos, com isso, negar a materialidade dos corpos, mas entendê-la como "efeito do poder, como o efeito mais produtivo do poder" (Butler, 2007:154). Ou seja, a ênfase aqui é no entendimento de que são práticas muito bem datadas, inclusive discursivas, que fazem com que determinados aspectos dos corpos - virtualidades ainda sem rosto, virtualidades que tomam forma a partir de determinadas práticas (Veyne, 2008) - se convertam, por exemplo, em definidores de gênero e de sexualidade, funcionando como definidores dos próprios sujeitos e de seus corpos.

A partir de tal entendimento, é possível pensar que a "simples" tão conhecida expressão "É um menino" ou "É uma menina" não dá nome a uma realidade dada de antemão, mas o próprio ato de nomear instaura "todo um processo de fazer desse corpo um corpo masculino ou feminino. Um processo que é baseado em características físicas que são vistas como diferenças e às quais se atribui significados culturais" (Louro, 2004:15-16). Ou seja, tal nomeação é "prescritiva, e não descritiva", isto é, produz "uma invocação performativa [com] efeitos protéticos: faz corpos" e sujeitos (Bento, 2006:88). Tal nomeação opera no sentido de fixar e naturalizar a "sequência sexo-gênero-sexualidade" (Louro, 2004:15) prescrita pelas normas regulatórias de gênero. Tais 
normas produzem corpos e sujeitos sexuados, generificados, sexualizados, normalizados.

"A lógica que supõe o sexo como um 'dado' anterior à cultura e lhe atribui um caráter imutável, a-histórico e binário" (Louro, 2004:16), não está garantida de uma vez por todas: "um trabalho pedagógico contínuo, repetitivo e interminável é posto em ação para inscrever nos corpos o gênero $e$ a sexualidade "legítimos" e, mais ainda, para naturalizar as normas de gênero (Louro, 2004:16). Os "corpos que importam", os "sujeitos legítimos" (Louro, 2004:15), "os corpos que pesam" (Butler, 2007) são aqueles que obedecem a tais normas, ou seja, são corpos que se materializam mediante sujeição às normas de gênero $e$ aos regimes de verdade $e$ de condutas a elas articulados. A necessidade de reiteração de tais normas aponta que

[...] é por meio das práticas, de uma interpretação em ato das normas de gênero, que o gênero existe. O gênero é performativo, adquire vida a partir das roupas que compõem o corpo, dos gestos, dos olhares, ou seja, de uma estilística definida como apropriada (Bento, 2006:90).

"Se o corpo é instável, flexível, retocável, plástico, será uma estética apropriada ao gênero identificado que lhe conferirá legitimidade para transitar na ordem dicotomizada dos gêneros" (Bento, 2006:24). Desfaz-se, assim a dicotomia natureza (corpo) e cultura (gênero), na medida em "são esses sinais exteriores, postos em ação, que estabilizam e dão visibilidade ao corpo" generificado (Bento, 2006:90).

Assim, estilhaça-se a ideia de um corpo "naturalmente dismórfico, como uma folha em branco, esperando o carimbo da cultura que, por meio de uma série de significados culturais, assume o gênero" (Bento, 2006:31). Nesse mesmo sentido, Butler (2007:154) problematiza o conceito de gênero, afirmando que "não se pode de forma alguma conceber o gênero como constructo cultural que é simplesmente imposto sobre a superfície da matéria - quer se entenda essa como o 'corpo', quer como um suposto sexo". Ainda nessa direção, a autora assinala que 
o gênero não está para a cultura, assim como o sexo está para a natureza; ele também é o meio discursivo cultural pelo qual "a natureza sexuada" ou "um sexo natural" é produzido e estabelecido como pré-discursivo (Butler, 2003:25).

Gênero é, então, aqui entendido como uma norma, "uma prática regulatória, que produz os corpos que governa, ou seja, toda força regulatória manifesta-se como uma espécie de poder produtivo, o poder de produzir [...] os corpos que ela controla" (Butler, 2007:153-154). É nessa direção que a materialidade do corpo não pode ser pensada separadamente da materialidade da norma regulatória, bem como a materialidade do sexo é obtida por meio da reiteração forçada de tal norma.

Assim, "nos constituímos como homens ou mulheres, num processo que não é linear, progressivo ou harmônico e que também nunca está finalizado" (Meyer, 2008:16). E são os modos como

se re-conhece e se distingue feminino de masculino, aquilo que se torna possivel pensar $e$ dizer sobre mulheres $e$ homens que vai constituir, efetivamente, o que passa a ser definido $e$ vivido como masculinidade e feminilidade em uma dada cultura, em um dado momento histórico (Meyer, 2008:14).

\section{(Re)existências corporais: desfazendo o gênero humano}

Quem tem a força de saber que existe. E no centro da própria engrenagem. Inventa a contra-mola que resiste (Ricardo; Mendonça,

1999).

Neste texto, como também em artigos anteriores (Vasconcelos, 2010, 2011), argumentamos que práticas institucionais, terapêuticas, corporais são acionadas para 
organizar/normalizar corpos no cenário das políticas públicas de saúde e, nesse processo, produzir saúde tende a envolver um ajustamento dos corpos às normas regulatórias de gênero. Mas é só isso? Essa é a sina a que estão fadados os arranjos corporais tecidos no seio das políticas de saúde?

Butler (2007:154) afirma que a materialização dos corpos feitos por meio de normas regulatórias de gênero "nunca é totalmente completa, que os corpos não se conformam nunca completamente às normas pelas quais sua materialidade é imposta". Os corpos são, assim, entendidos como "espaços de luta e de experimentação [...] como espaços conflitivos de submissão e de subversão" (Paraíso, 2011:149). Entre formas de sujeição e forças de experimentação, há um processo de formação corporal, por meio do qual os corpos assumem certa configuração estabilizada, certa forma que pode ser desfeita já que segue tensionada por forças, como apontam Rocha e Aguiar (2010:80):

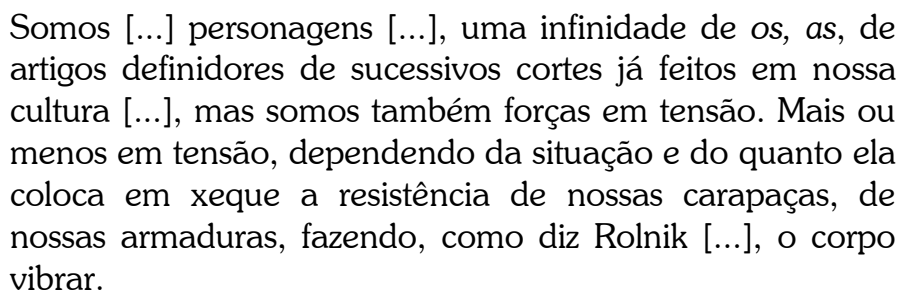

Se os corpos se tecem encarnando normas regulatórias de gênero, eles também (re)existem pela subversão delas. Se os corpos são construções político-culturais, são também construções político-éticas (Machado, Vasconcelos e Melo, 2012), na medida em que se lançam numa aventura sem bússolas de ensaiar outras formas, produzir novas normatividades e performatividades de gênero, experimentando o descaminho de se fazerem em outros lugares, menos afeitos à iluminação excessiva do poder (Foucault, 2006a).

São as instabilidades, as possibilidades, as aberturas dos processos de subjetivação que fazem com que o gênero seja 
"performático": reiterativo e citacional. [...] é aí que podemos subverter esses atos performáticos, abrir os corpos (Paraíso, 2011:165),

agenciar forças de (re)existência bem ali onde os mesmos vestem normas regulatórias, desfazendo-as.

Nesse mesmo sentido, as subjetividades produzidas podem ser pensadas não apenas como expressão corpórea dos regimes de verdade de uma dada época (Paulon, 2005), mas como expressividade corpórea que coloca esses regimes de verdade em questão, problematizando sentidos evidentes. A aposta ética foucaultiana (2006c) vai na direção de entender o sujeito como uma deriva, um efeito, um produto de uma subjetivação, não apenas como efeito da verdade do poder, mas com poder de instituir verdades. Ou seja, um sujeito com potência de inventar-se como sujeito por meio de práticas de si, não como técnicas de governo que o sujeita a outros, mas como exercícios que faz sobre si mesmo, pondo-se à prova, entendendo a vida como prova, como espaço de experimentação, como lugar de possibilidade de transformação de si, de invenção de outras formas e normas. Um sujeito que se dobra sobre si, produz novas superfícies, novos modos de prazer, novos modos de vestir gênero. Um sujeito que se inventa ao debochar da norma, ao brincar com a norma, ao vergá-la. Um dar forma à vida, um formar o eu, "uma prática de si e da verdade em que está em jogo a liberação do sujeito mais que seu aprisionamento em uma camisa de força da verdade" (Foucault, 2006c:618). Não apenas "o indivíduo sujeitado, mas a singularidade que se afirma na resistência ao poder - [...] as contracondutas" (Senellart, 2008:511).

Deleuze (1992:123) se pergunta

de onde vêm essas resistências? [...] como transpor a linha, como ultrapassar as próprias relações de força? Ou será que estamos condenados a um face a face com o Poder, seja detendo-o, seja estando submetidos a ele? (Deleuze, 1992:123). 
Fazendo referência a "um dos textos mais violentos $e$ também mais cômicos de Foucault", qual seja, A vida dos homens infames (Foucault, 2006a) -, o autor caminha na direção de indicar que a força de resistência ao exercício do poder governamental obstinado por tomar de assalto a produção de subjetividades reside justamente na produção e num embarcar em outros modos de subjetivação, outras formas de vida: "quando Foucault chega ao tema final da 'subjetivação', essa consiste essencialmente na invenção de novas possibilidades de vida" (Deleuze, 1992:114). O autor prossegue:

\begin{abstract}
Transpor a linha de força, ultrapassar o poder, isto seria como que curvar a força, fazer com que ela mesma se afete, em vez de afetar outras forças: uma "dobra" segundo Foucault, uma relação da força consigo que nos permita resistir, furtar-nos, fazer a vida ou a morte voltar-se contra o poder. [...] É o que Nietzsche descobria com a operação artista da vontade de potência, a invenção de novas "possibilidades de vida" (Deleuze, 1992:123).
\end{abstract}

Subjetividades teimam em dizer "não" à racionalidade da governamentalidade, subjetivações ousam brotar de rupturas bem no seio do jogo político. Governo de si por meio da produção de outras práticas de si que dão vazão a outras subjetivações, as quais descarrilam formas de ser já dadas, formatadas, enlatadas, desfazem o que foi feito de nós, inclusive por nós mesmos - esse parece ser um caminho frutífero de resistência ao biopoder operando em seu próprio seio: "E contra esse poder [...], as forças que resistem se apoiaram exatamente naquilo sobre que ele investe - isto é, na vida e no homem enquanto ser vivo" (Foucault, 2001b:136), nas normas regulatórias da vida dos corpos, inclusive as de gênero. Nessa mesma direção, Fahir Neto (2010), inspirado em Foucault, indica "a possibilidade da ética enquanto autoprodução de subjetividade":

O sujeito do último Foucault é um sujeito por fazer, potencialmente capaz de estabelecer, em relação a si 
mesmo, uma diferença contínua. Sua única determinação [...] é a potência de reconhecer, em si mesmo, um material ao qual pode ser dada uma outra forma. O que pré-existe, no sujeito ético de Foucault, não é a forma que ele é capaz de dar à sua própria materialidade, não é a forma que constitui a sua experiência, mas a simples capacidade de se experimentar sempre outro em relação a si próprio, à sua própria forma atual (Fahir Neto, 2010:201).

Nessa direção é que Machado, Vasconcelos e Melo (2012) assinalam que, além de se fazerem submissos a determinadas pedagogias culturais que lhes organizam, lhes marcam, lhes ensinam "boas" condutas, avaliam seu valor, os corpos tendem ao singular, ou melhor, à singularização (Guattari e Rolnik, 2000). Situando-se em fissuras do jogo do poder, corpos abandonam a adesão obediente às formas subjetivas prescritas por tais pedagogias, abrindo-se para outras práticas de si que não as bioidentitárias pautadas pela sujeição a um "eu" que, nos dias atuais, se expressa num "corpo", num "sexo", num "gênero", conformando subjetividades exteriorizadas (Ortega, 2008). Corpos recusam o que são e ensaiam a invenção de outros modos de existir, outras formas de subjetividade. Tensionando o corpo biológico e o linguístico, corpos (intensivos) sempre escapam às formas $e$ às significações em voga, sempre multiplicam seus sentidos, performances e experimentações. Alguns corpos, alguns "estados", ou melhor, alguns movimentos de corpos não são passíveis de nomeação, de adestramento, de identificação. Em regiões pouco afeitas à claridade da economia biopolítica em sua obsessão por marcações corporais, gestam-se corpos germinados por vidas que insistem em expandir-se, pelo convite a uma vida que pode mais, pelo menos mais do que esta: vida fadada a um corpo esquadrinhado, circunscrito, colado às significações, aos mapas políticos da linguagem, afeito à normalização, à incorporação de boas condutas postas em ação e reiteradas pelas pedagogias político-culturais (Vasconcelos e Seffner, 2011).

É na confluência de tais posicionamentos que a indagação acerca dos processos que organizam corpos e formam sujeitos 
(profissionais e usuári*s) no contexto das políticas públicas de saúde pode fazer sentido. Corpos organizados, sujeitos sujeitados, é só isso? Mediante nossas inserções em alguns pontos das políticas públicas de saúde, apostamos que não. Se pensamos as políticas de saúde como um território de ensino e organização corporais, também as concebemos como um "território de (des)aprendizagem" (Paraíso, 2011), em que corpos podem se abrir ao encontro com outros corpos e com o "outro" do corpo, desnaturalizando, assim, todo um longo histórico de enlatadas aprendizagens sobre processos corporais, institucionais $e$ terapêuticos. Nesse território, corpos experimentam processos de (des)aprendizagem menos afeitos ao governo das condutas, à fixação identitária e à formatação subjetiva (Foucault, 2006c).

Está-se, pois, falando da possibilidade de habitação de um território (des)humano fronteiriço, inclusive de análise, no qual se busca por corpos também fronteiriços, que se gestam problematizando os limites do humano, ou seja, que, por meio de suas performances, problematizam a naturalização de biopedagogias de formatação corporais, inclusive, as prescritas pelas normas de gênero. Sobre isso, aponta Deleuze (1992:60-61):

[...] sempre há uma fronteira, uma linha de fuga ou de fluxo, mas que não se vê porque ela é o menos perceptível. E no entanto é sobre essa linha de fuga que as coisas se passam, os devires se fazem, as revoluções se esboçam. [...] sempre serão encontradas linhas que vão desviar os conjuntos, [...] "ver as fronteiras", isto é, fazer ver o imperceptível. [...]. Toda uma micropolítica das fronteiras contra a macropolítica dos grandes conjuntos.

Aqui parece caber retomar a movimentação exposta acima de um corpo usuário de ad e de CAPS que, ao ousar desviar das normas higiênicas de saúde e das normas regulatórias de gênero, foi exposto à luz do poder de práticas especialistas em saúde. Uma "masculinidade sem homens" (Bento, 2006), um corpo híbrido, de fronteira que parodia o gênero por meio de "citações descontextualizadas de um referencial biológico" (Bento, 2006:85). 
Esse corpo, em suas feituras de gênero, é um corpo fronteiriço, um corpo que parece debochar das normas regulatórias. Sua expressão aponta para a desnaturalização dessas normas, sua exposição problematiza a evidência delas.

Num primeiro momento, num primeiro ímpeto, práticas de cuidado almejam tutelar esse corpo, corrigi-lo, purificá-lo, torná-lo mais claro, mais humano, "mais gênero". No entanto, no próprio bojo das políticas de saúde, ensaiam-se práticas de cuidado e de pesquisa também fronteiriças que almejam seguir esses corpos em suas fronteiras, intencionam habitar fronteiras, desenvolver, como diria Gilles Deleuze (1992) "uma micropolítica das fronteiras", região onde a vida brota e se esparrama, experimentações que, ao invés de "fundar" o sujeito, abre (des)caminhos para (des)subjetivações.

(Re)existências de gênero: o trajeto de vidas infames como a aqui descrita pede por ensaios, pela trama de arranjos corporais, inclusive do cuidado ofertado nos serviços de saúde e de pesquisas que parecem compor outras marcas que não só as de sujeição. Por entre "rostos verdadeiros" de masculinidades $e$ feminilidades, essa masculinidade sem homem que habita o ambiente "masculinizado" de um serviço de saúde, a saber, um CAPS ad, se tece como masculinidade infame: esse masculino que subverte um corpo que careceria ser feito feminino, que necessitaria tecer-se reiterando a sina de um determinado feminino que deveria ser seu destino, ali deixa rastros que trazem consigo a força de desfazer o já feito e o já dado pelas normas regulatórias de gênero (Paraíso, 2011), de interferir na paisagem humana instituída como única, legítima, caminho reto e universal, mostrando com o seu corpo que "há muitas possibilidades de se [des]fazer gênero" (Bento, 2006:16).

Nessa direção, em vez de se seguir submetendo corpos que ousam outras performances de gênero a práticas sanitáriopedagógicas e a análises que tendem a identificá-los e fixá-los como anormais - ou seja, como corpos que precisam ser conduzidos a fim de recompor o caminho da retidão dos humanos sexuados-generificados-(hetero)sexualizados, encontros 
clandestinos, menos afeitos à excessiva iluminação do biopoder com esses corpos trazem, bem ali no bojo das políticas e do cuidado em saúde, a possibilidade de (des)aprendizagem de (des)subjetivação, de abertura de corpos para o ensaio de outras formas de vida - inclusive o corpo institucional, do cuidado e da pesquisa. A partir desses encontros, os corpos podem, assim, produzir saúde despindo-se do que foi aprendido por normas regulatórias (de gênero) e ensaiar outras performances mais mestiças, mais afeitas à hibridação, à aventura de outras experimentações corporais.

\section{Vibrações do conceito de gênero}

Agonizo se tento Retomar a origem das coisas Sinto-me dentro delas e fujo Salto para o meio da vida Como uma navalha no ar Que se espeta no chão

Não posso ficar colado à natureza como uma estampa E representá-la no desenho que dela faço Não posso Em mim nada está como é Tudo é um tremendo esforço de ser (Ricardo; Mendonça, 1999).

Uma vez que gênero (assim como as subjetividades, os fazeres, os prazeres e os saberes a ele articulados) é construído por práticas sociais muito bem datadas (inclusive práticas de pesquisa e de produção de conhecimento), pode-se dizer que é por meio de nossas experiências, na imanência das práticas e das lutas inscritas em nosso tempo histórico, que incidem problematizações $e$ atualizações do conceito de gênero. Todavia, para que tal conceito funcione como intercessor (Deleuze, 1992), ou seja, para que por meio dele se possa interceptar, derivar, desviar, correlacionar, 
intervir - no sentido lourauniano (1995): mexer no que parece óbvio, produzindo desnaturalizações -, ele não pode pesar na bagagem. Ao contrário, precisa servir de norte para se entrar onde se quiser, desde que as entradas apontem múltiplas saídas, para adentrar mesmo que sejam regiões ainda por vir (Deleuze e Guattari, 1995).

Nessa direção, cabe perguntar: daria para pensar a categoria gênero funcionando não em prol da organização humana do corpo em suas classificações binário-dicotômicas, mas como um operador de análises preocupadas em seguir intensidades e afetos que atravessam e transformam o corpo? Daria para produzir outros modos de pensar gênero que não acoplado à sequência corpo humano-sexo-genitália-gênero-sexualidade? A partir do conceito de gênero, poderíamos nos aventurar em outras rotas, outros trânsitos, hibridações e não em conformações identitárias? Qual a força do conceito de gênero para as nossas pesquisas $e$ análises?

A essa altura, parece ser importante retomar a afirmação sobre a historicidade do feminismo e do conceito de gênero gestado em seu bojo. A esse respeito, Corrêa (2001:24) assinala a "clara articulação entre o feminismo dos anos setenta $e$ a emergência dos estudos de gênero dos anos noventa". Foi nesse mesmo contexto em que se passou a utilizar gênero como sinônimo de mulheres, a fim, como afirma Scott (1995:75), de se "obter reconhecimento político deste campo de pesquisas [...], pois 'gênero' parece se ajustar à terminologia científica das ciências sociais, dissociando-se, assim da política (supostamente ruidosa) do feminismo". Corrêa (2001:25), discutindo o cenário brasileiro, aponta que analisar a articulação entre feminismo e formulação do conceito de gênero é importante porque,

[...] nós, pesquisadoras, éramos também militantes e [...] se nos desiludimos com algumas das crenças inscritas em nossas palavras de ordem, não foi porque nosso compromisso maior era com fazer ciência social, mas sim porque nosso compromisso maior era com a tentativa de compreender a sociedade brasileira, para mudá-la. 
A desilusão parece advir da prática de uma militância identitária, uma vez que, nesse cenário, ambos, feminismo e gênero, "ao agir em nome das mulheres, invocam a mesma diferença que pretendem negar" (Melo, 2008:557): a diferença sexual. Desse modo, por meio da prática de tal militância, a afirmação da diferença (identitária) se traduz em reificação de dicotomias, separações e segregações. Desse modo, o jogo de poder permanece o mesmo ao qual, a partir da militância, se tenta contrapor: não apenas rejeição do diferente, mas, sobretudo, "obsessão pela diferença" (Veiga-Neto, 2001:107) para, no final, traduzi-la, fixá-la, subsumi-la, identificá-la, torná-la conhecida, igual, universal, humana, construindo e petrificando, nesse caso, o sujeito mulher. Dessa forma, subsiste o primado do uno, do ser, que deve supostamente tornar-se "múltiplo": mulheres. ${ }^{5}$ No que se refere ao movimento feminista, Butler (2003:34-35) aponta que

a insistência sobre a coerência e a unidade da categoria mulheres rejeitou efetivamente a multiplicidade das interseções culturais, sociais, políticas e contingenciais em que é construído o espectro concreto das "mulheres".

A partir de tais considerações, ensaia-se um caminho rumo à ampliação e à complexificação das análises de gênero empreendidas, o qual diz respeito a:

1) Desfazer a sinonímia gênero-mulher, a partir da qual se tende a focalizar os estudos exclusivamente sobre condições de vida das mulheres. Ao invés disso, analisar processos, estratégias e práticas político-culturais que, de forma articulada, "produzem e/ou educam indivíduos como mulheres e homens de determinados tipos" (Meyer, 2008:18). Ou seja, pensar o gênero

5 Uma vez que o sexo é entendido aqui como construído mediante materialização de normas de gênero, ou seja, como uma objetivação de práticas determinadas, a mulher "não é um, nem múltiplo [...] pela simples razão de que não existe; existem, unicamente, múltiplas objetivações. [...] Só a ilusão de objeto natural cria a vaga impressão de unidade" (Veyne, 2008:256-257). 
cadernos pagu (44) Michele de F. Faria de Vasconcelos e Fernando Seffner 289

como categoria relacional, como "elemento constitutivo de relações sociais baseadas nas diferenças percebidas entre os sexos" (Scott, 1995:86).

2) Considerar a relevância em se articular a categoria "gênero" a outros marcadores socioculturais, uma vez que "cada uma dessas articulações produz modificações importantes nas formas pelas quais as feminilidades ou as masculinidades são, ou podem ser, vividas e experimentadas" (Meyer, 2008:17). Desse modo, afirma-se a existência de "muitas e conflitantes formas de definir e viver a feminilidade e a masculinidade" (Meyer, 2008:17).

3) Afastar-se de abordagens que reduzem gênero a papéis e funções de homens e mulheres. Ao contrário, partir do entendimento de que o gênero atravessa a constituição e o funcionamento de instituições, símbolos, normas, leis, serviços assistenciais, políticas sociais, corporais e de subjetivação de uma sociedade (Meyer, 2008). E, assim, pensá-lo como categoria analítica de poder, um campo "no interior do qual o poder é articulado" (Scott, 1995:88).

Nessa mesma direção, a categoria "masculinidade" não equivale nem se restringe aos "homens", nem a categoria "feminilidade", às "mulheres". A partir da perspectiva aqui proposta, ao intentar discutir produção de masculinidades $e$ feminilidades, não se focaliza nos homens nem nas mulheres, mas se pensa tal produção - arranjos/jogos de masculinidades $e$ feminilidades - nas políticas sociais, nos serviços, bem como em corpos "classificados" como homens e como mulheres.

Tateando mais um desdobramento no conceito, não entendemos que os homens $e$ as mulheres, nem os marcadores sociais - identitários, diga-se de passagem - a eles/elas atribuídos (de classe, raça, religião, faixa etária, de gênero, de sexualidade etc.), nem mesmo o humano, ensejem o limite para o jogo performático de gênero (Bento, 2006; Butler, 2007). Em outros termos, pretendemos analisar em nossas pesquisas como se dá a negociação de versões que produzem um jogo de práticas, inclusive discursivas, que conferem materialidade a masculinidades e feminilidades em um campo experimental. $\mathrm{O}$ 
modo de funcionamento das políticas e dos serviços de saúde, o próprio espaço físico, os documentos que ali circulam, *s profissionais e seus modos de cuidados, a forma como se habita o serviço, os movimentos de resistência dos corpos que ali circulam, todo esse entorno encarna, inscreve, prescreve masculinidades $e$ feminilidades como também faz as mesmas vazarem, seguirem outras rotas.

4) Pensar o gênero como categoria plural. Ainda na direção de complexificação das análises de gênero, cabe discutir que, quando se pensa gênero como uma categoria relacional, tende-se a subsumi-lo a "um 'relacional de dois' calcado no referente dos sexos" (Bento, 2006:77), referente que tende, assim, a seguir naturalizado. Dessa forma, o binarismo entre dois sexos, dois gêneros e duas sexualidades permanece indicando o limite para análises e intervenções.

Nessa direção, mesmo que se aponte que os desenhos de gênero se fazem por meio de caminhos singulares em que vários marcadores sociais (de gênero, de sexualidade, de raça/etnia, de religião, de nacionalidade, de região, faixa etária etc.) se entrecruzam, o limiar desse tipo de análise parece ser o de fincar os corpos aos definidores socioculturais. Tende-se, assim, a partilhar da mesma lógica dicotômica que classifica, hierarquiza, naturaliza, fixa, produz identidades como modo de sujeição. Além disso, mediante a fixação dos corpos em termos binários, colocase entre parênteses, desautoriza-se a existência do nomadismo e hibridismo que ocorre no "entre", no "meio" desses polos, região habitada por intensidades que resistem à purificação e que trazem consigo a possibilidade de desestabilizar tais fronteiras identitárias.

Lembremos, pois, que o espaço corporal é conflitivo, ou seja, se, por um lado, o corpo é produzido por meio de ensinamentos, prescrições, marcações socioculturais, por outro, ele é afeito à insubmissão, à mestiçagem, ao borramento das fronteiras dos marcadores socioculturais, à produção de formas para as quais não se tem moldes. Nesse sentido, este texto se engaja com análises que se dão na contramão de perspectivas que estudam o gênero como categorial universal ou relacional de dois 
termos pré-fixados, uma vez que não se trata da análise de relações "naturais", duais, binárias, mas da análise de uma relação constitutiva, contemporânea aos termos e seus movimentos.

Assim, ao invés de seguir pensando em duas formas masculino e feminino, homem $e$ mulher - que antecedem a relação, se aposta na ideia de que as formas não se separam do processo de formação, pois as mesmas continuam a ser encharcadas pelo ambiente relacional, como plano das forças: há um processo de formação, por meio do qual as formas assumem uma dada configuração que pode ser desfeita (Kastrup, 2008). Afirma-se, assim, o primado não dos termos, mas da região relacional entre eles. É nesse sentido que pensamos o gênero como categoria relacional, apostando no primado da relação $e$ dos múltiplos sentidos e possibilidades de experimentar gênero que habitam esse espaço entre os termos masculino e feminino, mulher e homem. E essa dimensão processual do espaço entre os termos não desaparece nas formas que os termos tomam. Desse modo é que pensamos o gênero como categoria plural (Bento, 2006) e almejamos segui-lo ali onde ele se multiplica e se desfaz (Butler, 2007): no meio, nos interstícios, nas pegadas das forças que atravessam os corpos, desfiguram as formas humanas dadas $e$ constroem o "outro" do corpo em suas multiplicidades de feituras de gênero. No plano do entre, gestam-se insubmissões, inscrevemse as afetações, a produção de laços e a inventividade de relações, conexões, subjetivações, sociabilidades que não as prescritas pelo Estado e pelo mercado. Nesse plano, se pode descompor a guerra entre os sexos e "levar uma guerra dos habitantes dos devires contra os viciados em gênero, inclusive e, antes de mais nada, na arena de nossa própria subjetividade" (Rolnik, 1998:68).

Se a categoria gênero tem sido por nós utilizada para apontar no seio das políticas públicas de saúde e das práticas de saúde aí produzidas, processos de formatação corporais, tem sido também, em nossas pesquisas, usada para rastrear montagens corporais brincantes que, ousando habitar zonas fronteiriças, parecem funcionar debochando de tais formatações, ao mostrar que elas também não passam de produções que não têm nada a 
ver com "naturezas" $e$ "essências" e que, assim, podem ser desfeitas. Em outros termos, o corpo em suas feituras de gênero pode ser abertura ao devir e à encarnação de formas originais, bem ali em terrenos afeitos ao cerceamento de tais formas, como o do cuidado produzido no seio de políticas públicas.

Nessa mesma direção, tem nos parecido ser interessante "dedicar uma atenção especial às performances que provocam fissuras nas normas de gênero" (Bento, 2006:78), fazendo vacilar o imperativo dicotômico: um sexo, macho ou fêmea, um corpo, masculino ou feminino, uma sexualidade, "hetero" ou "homo". Tais performances - contracondutas, diria Foucault (2008a) trazem consigo a possibilidade de desafiar o sistema binário de gênero $e$ a traçar caminhos outros que não os restritos a filiações em um dos lados das extremidades e à reivindicação por legitimidade de uma "identidade" de gênero para corpos e sujeitos "dissidentes", trajetos que não se conformam em simplesmente lutar pelo reconhecimento de uma identidade de gênero diferente da "natural", mas tão fixa, restritiva e regulada quanto.

Em outros termos, talvez seja preciso lutar, isso sim, pela possibilidade de habitação de zonas de fronteiras, do espaço híbrido do "entre" extremidades, situando as análises e experimentações logo ali onde se encontram forças em tensão, as quais fazem o corpo vibrar. Nesse espaço relacional, parecem se gestar subjetividades nascentes, embrionárias, corpos em criação, corpos intensivos. Então, talvez seja preciso brigar, inclusive por meio da pesquisa (e contra alguns modos de se fazer $e$ pensar pesquisa), para que trânsitos não sejam barrados, identificados, trânsitos corporais, inclusive entre gêneros (Bento, 2006; Louro, 2004). Tentar, com a pesquisa, produzir um território de habitação fronteiriça, em que o que importa não é mais o verbo ser, com toda sua carga identitária e de filiação em um dos lados das dicotomias criadas, mas o que conta é a conjunção " $e$ ", pois, o " $E$ não é nem um nem o outro, é sempre entre os dois, é a fronteira" (Deleuze, 1992:61).

Ao situar as análises nas regiões fronteiriças, no espaço virtual onde a vida se desdobra em potência, parece que a força 
das análises de gênero prossegue e se expande, na medida em que gênero pode, assim, funcionar como um dispositivo conceitual e político importante, quando o que se almeja é produzir pesquisas-intervenções que tragam a possibilidade de problematizar arranjos sociais $e$ institucionais vigentes $e$ as hierarquias e desigualdades deles decorrentes (Meyer, 2008).

\section{Referências bibliográficas}

AVELINO, N. Apresentação: Foucault e a anarqueologia dos saberes. In: FoucAult, M. Do governo dos vivos. São Paulo, Centro de Cultura Social; Rio de Janeiro, Achiamé, 2011, pp.17-38.

BENTO, B. A reinvenção do corpo: sexualidade e gênero na experiência transexual. Rio de Janeiro, Garamond, 2006.

BUTLER, J. Corpos que pesam: sobre os limites discursivos do "sexo". In: LOURO, G. L. (org.). O corpo educado: pedagogias da sexualidade. Belo Horizonte, Autêntica, 2007, pp.151-172.

. O parentesco é sempre tido como heterossexual? Cadernos Pagu (21), Campinas-SP, Núcleo de Estudos de Gênero-Pagu/Unicamp, 2003, pp. 219-260.

CANGuilhem, G. O normal e o patológico. Rio de Janeiro, Forense Universitária, 1978.

CARVALHO, S. Reflexões sobre o tema da cidadania e a produção de subjetividade no SUS. In: CARVAlHO, S.; BARroS, M.; Ferigato, S. (orgs). Conexões: saúde coletiva e políticas da subjetividade. São Paulo, Aderaldo \& Rothschild, 2009, pp.23-41.

CoRAzZA, S.; SILVA, T. Manifesto por um pensamento da diferença na educação. In: Composições. Belo Horizonte, Autêntica Editora, 2003, pp.9-18.

CORRÊA, M. Fantasias corporais. In: PISCITELLI, M.; GREGORI, M. F.; CARRARA, S. Sexualidade e saberes: convenções e fronteiras. Rio de Janeiro, Garamond, 2004, pp.173-182.

- Gênero e saúde: campo em transição. In: BRUSCHINI, C.; UnBEHAUM, S. (orgs.). Gênero, democracia e sociedade brasileira. São Paulo, FCC/Editora 34, 2002, pp.357-388. 
. Do feminismo aos estudos de gênero no Brasil: um exemplo pessoal. Cadernos Pagu (16), Campinas-SP, Núcleo de Estudos de Gênero-Pagu/Unicamp, 2001, pp.13-30.

DeleuZE, G. Conversações (1972-1990). São Paulo, Editora 34, 1992, (Coleção Trans).

Deleuze, G.; GuATTARI, F. 28 de novembro de 1947 - Como criar para si um corpo sem órgãos. In: . Mil platôs: capitalismo e esquizofrenia. vol. 3. Rio de Janeiro, Editora 34, 1996, pp.9-32. ; . Mil platôs: capitalismo e esquizofrenia. vol. 1. Rio de Janeiro, Editora 34, 1995.

FARHI NETO, L. Biopolíticas:as formulações de Foucault. Florianópolis, Cidade Futura, 2010.

Foucault, M. Do governo dos vivos. São Paulo, Centro de Cultura Social; Rio de Janeiro, Achiamé, 2011.

. O sujeito e o poder. In: DREYFus, H. L.; RABINOW, P. Michel Foucault: uma trajetória filosófica: para além do estruturalismo e da hermenêutica. Rio de Janeiro, Forense Universitária, 2010, pp.273295. 2008a.

Segurança, território, população. São Paulo: Martins Fontes, . Nascimento da biopolítica. São Paulo, Martins Fontes, 2008b.

. A vida dos homens infames. In: MotTA, M. B. (org.). Ditos \& Escritos IV: estratégia, saber-poder. Rio de Janeiro, Forense Universitária, 2006a, pp.203-222.

. "Omnes et Singulatim": uma crítica da razão política. In: MOTTA, M. B. (org.). Ditos \& Escritos IV:estratégia, saber-poder. Rio de Janeiro: Forense Universitária, 2006b, pp.355-385.

. A hermenêutica do sujeito. São Paulo: Martins Fontes, 2006c.

. O verdadeiro sexo. In: MotTA, M. B. (org.). Ditos \& Escritos V:ética, sexualidade, política. Rio de Janeiro: Forense Universitária, 2006d, pp.82-91.

. Vigiar e punir. Petrópolis, Vozes, 2004. 
cadernos pagu (44) Michele de F. Faria de Vasconcelos e Fernando Seffner 295

. História da sexualidade I: a vontade de saber. Rio de Janeiro: Edições Graal, 2001a.

. Microfísica do poder. Rio de Janeiro, Edições Graal, 2001b.

. Os anormais. São Paulo, Martins Fontes, 2001c.

. Em defesa da sociedade. São Paulo, Martins Fontes, 1999. Coleção Tópicos.

GuATtARI, F. Caosmose:um novo paradigma estético. São Paulo, Editora $34,2000$.

; ROLNIK, S. Micropolítica: cartografias do desejo. Petrópolis, Vozes, 2000.

HARWOOD, V. Theorizing biopedagogies. In: WRIGHT, J.; HARWOOD, V. (Eds.). Biopolitics and the "obesity epidemic" - governing bodies. New York, NY, Routledge, 2009, pp.15-30.

KASTRUP, V. O método da cartografia e os quatro níveis da pesquisaintervenção. In: CASTRO, L. R.: BESSET, V. L. Pesquisa-intervenção na infância e na juventude. Rio de Janeiro, Nau, 2008, pp.465-489.

LAQUEUR, T. A descoberta dos sexos. In: . Inventando o sexo: corpo e gênero dos gregos a Freud. Rio de Janeiro, Relume Dumará, 2001, pp.189-240.

LOPES, M. Norma, inclusão e governamentalidade neoliberal. In: Branco, G. C.; Veiga-Neto, A. (orgs). Foucault: filosofia \& política. Belo Horizonte, Autêntica Editora, 2011, pp.283-298.

LOURAU, R. A análise institucional. Petrópolis, Vozes, 1995.

LOURO, G. L Pedagogias da sexualidade. In: __. O corpo educado:pedagogias da sexualidade. Belo Horizonte, Autêntica Editora, 2007, pp.7-34.

. Um corpo estranho: ensaios sobre sexualidade e teoria queer. Belo Horizonte, Autêntica Editora, 2004.

Machado, D.; Vasconcelos, M. F. F.; Melo, A. R. O corpo como fio condutor para ampliação da clínica. Polis e Psique, vol. 2, número temático, pp. 147-170, 2012. 
296 A pedagogia das políticas públicas de saúde

MELO, É. Feminismo: velhos e novos dilemas. Uma contribuição de Joan Scott. Cadernos Pagu (31), Campinas-SP, Núcleo de Estudos de Gênero-Pagu/Unicamp, 2008, pp.553-564.

MEYER, D. E. Gênero e educação: teoria e política. In: LOURO, G. L.; FELIPE, J.; GOELlNER, S. V. (org.). Corpo, gênero e sexualidade: um debate contemporâneo na educação. Petrópolis, Vozes, 2008, pp.927.

ORTEGA, F. O corpo incerto: corporeidade, tecnologias médicas e cultura contemporânea. Rio de Janeiro, Garamond, 2008.

PARAISO, M. A. Raciocínios generificados no currículo escolar e possibilidades de aprender. In: LeITE, C. et al. (org.). Políticas, fundamentos e práticas do currículo. Porto, Porto Editora, 2011, pp.147-160.

PASSETTI, Edson. Anarquismos e sociedade de controle. São Paulo, Cortez Editora, 2003.

PAULON, S. A análise de implicação como ferramenta na pesquisaintervenção. Psicologia e Sociedade, Minas Gerais, 17 (3), pp.18-25, 2005.

RochA, M. L.; AgUiAR, K. F. Entreatos: percursos e construções da piscologia na rede pública de ensino. Estudos e Pesquisas em Psicologia, Rio de Janeiro, vol. 10, n 1, p.68-84, 2010.

ROLNIK, S. Machos \& fêmeas. In: LINS, D. (org.). A dominação masculina revisitada. Campinas, Papirus, 1998b, pp.69-71.

SCHEINVAR, E. Biopolítica e judicialização das práticas de direitos: conselhos tutelares em análise. In: BRANCO, G. C.; VeIGA-NETO, A. (orgs). Foucault: filosofia \& política. Belo Horizonte, Autêntica Editora, 2011, pp.143-152.

ScotT, J. Gênero: uma categoria útil de análise histórica. Educação e Realidade, Porto Alegre, vol. 20, n² 2, 1995, pp.71-100.

SEFFNER, F. Derivas da masculinidade: representação, identidade e diferença no âmbito da masculinidade bissexual. Tese de doutorado, PPGEDU

UFRGS, 2003 [http://www.lume.ufrgs.br/bitstream/handle/10183/4340/000399778.p df?sequence $=1$ - acesso em: 11 de julho de 2013]. 
cadernos pagu (44) Michele de F. Faria de Vasconcelos e Fernando Seffner 297

- Discutindo a relação: teorias educacionais, pensamento pedagógico e estratégias de prevenção na experiência brasileira de luta contra a AIDS. In: PAIVA, V.; PUPO, L. R. e SEFFNER, F. (Orgs.) Vulnerabilidade e Direitos Humanos Promoção e Prevenção da Saúde. Livro III - Pluralidade de Vozes e Inovação de Práticas. Curitiba, Juruá Editora, 2012, pp.51-78.

Senellart, M. Situação dos cursos. In: Foucault, M. Segurança, território, população. São Paulo, Martins Fontes, 2008, pp.495-537.

VASCONCELOS, M.F.F. de. A infâmia de Quincas: (Re)existências de corpos em tempos de biopolítica. Tese de Doutorado, Faculdade de Educação, Universidade Federal do Rio Grande do Sul, Porto Alegre, 2013.

. Como tantas: Maria. Educação e Realidade. Porto Alegre, vol. 35, no 3, set./dez., 2010, pp.277-302.

; SEFFNER, F. Do que vale para o que pode: corpos de Quincas Berro Dágua. Educação e Realidade, vol. 36, n 3, , set./dez., 2011, pp.883-910.

VeigA-Neto, A. Incluir para excluir. In: LARROSA, J.; SkLiAR, C. (org.). Habitantes de Babel: políticas e poéticas da diferença. Belo Horizonte, Autêntica Editora, 2001, pp.105-118.

VEYNE, P. Como se escreve a história: Foucault revoluciona a história. Brasília, Universidade de Brasília, 2008. 